\title{
La gastronomía, un en-sueño nacional: dificultades y potencialidades del plato nacional
}

\section{Gastronomy, a national dream: difficulties and potentials of the national dish}

Fabián Andrés Llano*

Universidad Distrital Francisco José de Caldas

Bogotá, Colombia

*llanofabian@hotmail.com

\section{Articulo de reflexión}

Recepción: 30 de julio de 2019. Aceptación: 21 de agosto de 2019

\section{Cómo citar este artículo}

La gastronomía, un en-sueño nacional: dificultades y potencialidades del plato nacional. Sosquua 1(1), 91-95. Recuperado a partir de http://cipres.sanmateo.edu.co/index.php/sosquua 
Plantear la pregunta por el patrimonio gastronómico implica pensar, en primer lugar, en las posibilidades de concebirlo como un objeto de estudio. Esta situación abre la oportunidad para una reflexión epistemológica, teórica y práctica sobre el hecho culinario. Aquí aparecen las discusiones antropológicas, sociológicas e históricas para legitimar el estudio sobre el significado de cocinar y los diferentes debates sobre las perspectivas, tendencias y enfoques de abordaje disciplinar e interdisciplinar. En segundo lugar, esta discusión permite vincular las relaciones del acto de cocinar con los elementos territoriales. Aquí son importantes enfoques como la geografía humana, la historia cultural de los alimentos, las prácticas culturales y toda suerte de recorridos por las ciencias sociales y humanas desde intercambios conceptuales y ejercicios de tipo inter y multidisciplinar.

En efecto, esto significa preguntarse por la legitimidad de los alimentos y los contextos de su producción y, por supuesto, interrogarse por las formas de estructuración de la identidad, así como su potencial para representar a quienes consumen determinados alimentos. En este primer plano aparece la pregunta obligada sobre el plato nacional y las múltiples formas que adquiere la simbolización del alimento. Más que abordar la discusión en un plano abstracto, y obviar las dificultades que agrega a esta definición el tema de la globalización con la proliferación de alimentos procesados e hiperindustrializados, es importante reconocer las prácticas culinarias reafirmadas sobre los ritos y la tradición oral de recetas que se pasan de generación a generación (Llano, 2017).

Esto permite evidenciar, para el caso colombiano, cómo la definición de un plato nacional pasa por la enorme contradicción de una riqueza gastronómica que, si bien puede convertirse en la base para fortalecer las representaciones culturales del país por medio de la difusión y puesta en valor de la cocina colombiana, también genera 
ciertas dificultades al momento de la elección de construcciones culturales con la legitimación del patrimonio gastronómico colombiano.

Preguntas como ¿cuál es el alimento (o la preparación) que aglutina la representación por lo nacional? o ¿cuál es el plato que nos identifica como colombianos? suelen traer más interrogantes que respuestas concretas. Para este caso habría que explorar nuevas categorías para pensar el patrimonio gastronómico en su calidad más bien de patrimonios frágiles y patrimonios porosos (Llano, 2014). La última conceptualización está relacionada con aquellas costumbres, rituales y cualquier manifestación cultural asociada a las preparaciones de los alimentos que por lo general son transmitidas por tradición oral.

Sin embargo, desde la fragilidad están en riesgo de desaparecer o ser olvidadas por las nuevas generaciones que asumen nuevas subjetividades y formas de saborear el mundo. Estas formas de consumo de los alimentos, asociada a la proliferación de alimentos procesados, recubren la superficie porosa de estos patrimonios ricos en representaciones y significados culturales. Expresan múltiples vasos comunicantes y relaciones culturales susceptibles de ser rastreadas y conceptualizadas desde una historia cultural de los alimentos y las preparaciones (Llano, 2013).

El riesgo cada vez mayor de petrificar estos patrimonios desde una superficie lisa y homogénea, como la globalización económica y cultural, puede explicar el fenómeno de la convivencia de la comida tradicional, las diferentes presentaciones visibles en los supermercados y, con ello, las prácticas como el enlatado y la conserva. En efecto, la comida típica se presenta como una serie de repeticiones, al estilo de las sopas de tomate Campbell's, del artista Andy Warhol. En el supermercado es posible observar reiterativamente el tamal y la 
lechona enlatados, que por supuesto se mezclan con galletas, manzanas y duraznos debidamente empacados. Estas contradicciones culturales y alimentarias permiten ampliar la discusión sobre la legitimidad de los alimentos, su valor cultural e histórico y, sobre todo, la pregunta por la identidad y la soberanía alimentaria.

Habría que preguntarse ¿por qué es tan difícil reconocer estos patrimonios gastronómicos en nuestro país y cuál es la razón para que no aparezcan claramente en la experiencia cotidiana y se presenten más bien como repertorios difusos? También, ¿cuál es el valor cultural de estos patrimonios y de qué manera se asocian con unos territorios, donde perviven y se niegan a desaparecer? ¿en qué consiste esta resistencia cultural? Estas y otras preguntas permiten vislumbrar la gran cantidad de productos de diferente procedencia regional que puedan ser ofertados en los diferentes restaurantes del país, con una clara invitación directa a visitar el lugar de procedencia del producto. La experiencia colombiana puede ser rastreada y difundida como en el caso peruano, al estilo del documental de Ernesto Cabellos "de ollas y sueños".

Finalmente, es pertinente preguntarse por la paulatina desaparición de los alimentos autóctonos, la ausencia cada vez más palpable de los productos de la tierra en las preparaciones culinarias y el aumento cada vez más acelerado de la comida procesada, industrializada y desabrida que se encuentra en los supermercados más cercanos. Esta dinámica, tan cotidiana, puede esconder ciertas diferencias y prestamos culinarios que siguen posicionando la cultura foránea por encima de los referentes culturales locales. 


\section{Lista de referencias}

Cabellos, E. (2009). De ollas y sueños. Recuperado de http://guarango. pe/dols/sinopsis.html

Llano, F. (2017). Gastronomía, turismo y potencialidades territoriales: el plato minero y la salazón, bases para el turismo alimentario en Nemocón. Cuadernos de Geografía: Revista Colombiana de Geografía, [S.I.], v. 26, n. 2, p. 295-306, jul. 2017. ISSN 2256-5442. Recuperado el 28 noviembre 2018. Disponible en: <https://revistas.unal.edu. co/index.php/rcg/article/view/59280>.

Llano, F. (2014). Lo que no se narra se olvida, recuperación de la cocina tradicional en Cundinamarca y Boyacá. Bogotá: Servicio Nacional de Aprendizaje (SENA). Recuperado el 19 de enero de 2015. Disponible en: https://www.academia.edu/24307949/Lo_que_no_ se_narra_se_olvida.

Llano, F. (2013). Turistas comensales: patrimonio gastronómico y turismo alimentario en Nemocón y Ubaté. Bogotá: Corporación Unificada Nacional de Educación Superior (CUN). Recuperado el 30 de noviembre de 2014. Disponible en: https://www.academia. edu/10681086/Turistas_comensales. 